\title{
Effect of Ag Capping Layer on the Emission Characteristics of Transparent Organic Light-emitting Devices with $\mathrm{Ca} / \mathrm{Ag}$ Double-layer Cathodes
}

\author{
Chan-Jae Lee \\ Display Components \& Materials Research Center, Korea Electronics Technology Institute, Seongnam 463-816, Korea \\ Dae-Gyu Moon ${ }^{+}$ \\ Department of Materials Engineering, Soonchunhyang University, Asan 336-745, Korea
}

Received October 29, 2013; Accepted January 6, 2014

\begin{abstract}
We have investigated the effects of an Ag capping layer on the emission characteristics of transparent organic light-emitting devices with Ca/Ag double-layer cathodes. The thickness of the Ag layer was varied from 10 to 30 $\mathrm{nm}$, whereas the Ca was fixed to be a $10 \mathrm{~nm}$ in the Ca/Ag structure. The luminance and current efficiency on the cathode and anode sides are significantly dependent on the Ag thickness. For example, the current efficiency on the anode side increases from 8.4 to $11.7 \mathrm{~cd} / \mathrm{A}$, whereas, on the cathode side, it decreases from 3.2 to $0.2 \mathrm{~cd} / \mathrm{A}$ as the $\mathrm{Ag}$ thickness increases from 10 to $30 \mathrm{~nm}$. These changes in emission characteristics were investigated by measuring electroluminescence, transmission, and reflection spectra.
\end{abstract}

Keywords: Organic light-emitting devices, Transparent OLED, Transparent cathode, Ca/Ag cathode

\section{INTRODUCTION}

Organic light-emitting devices (OLEDs) consisting of functional organic thin films between the cathode and the anode have attracted much attention during the past few decades because they can provide high-performance displays and lighting applications due to their superior characteristics, such as wide viewing, fast response, and high brightness [1,2]. Because the organic layers in OLEDs are typically transparent in the visible range [3], new applications, such as see-through displays and lighting for automobile windshields, architectural and shop windows, and eyewear can be realized if both electrodes are transparent. Indium tin oxide (ITO), which is widely used as an anode material for OLEDs, has a high transparency; therefore, the use of transparent

${ }^{\dagger}$ Author to whom all correspondence should be addressed: E-mail: dgmoon@sch.ac.kr

Copyright $@ 2014$ KIEEME. All rights reserved. This is an open-access article distributed under the terms of the Creative Commons Attribution Non-Commercial
License (http:///creativecommmons.org/licenses/by-nc/3.0) which permits unrestricted noncommercial use
distribution, and reproduction in any medium, provided the original work is properly cited

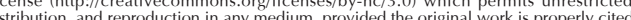

cathodes in realizing transparent OLEDs has become an area of interest. Since the first report on thermally evaporated $\mathrm{LiF} / \mathrm{Al} / \mathrm{Ag}$ semitransparent cathodes by Hung et al. [4], many researchers have focused on the evaporated semitransparent metal cathodes because they provide highly transparent and efficient OLEDs without rendering damage to the underlying organic layers. Several semitransparent metal cathodes of $\mathrm{Sm} / \mathrm{Au}, \mathrm{Yb} / \mathrm{Ag}$, $\mathrm{Ca} / \mathrm{Mg}$, $\mathrm{Ca} / \mathrm{Ag}, \mathrm{Ba} / \mathrm{Ag}$, and $\mathrm{Sr} / \mathrm{Ag}$ have been proposed [5-11]. Doublelayer $\mathrm{Ca} / \mathrm{Ag}$ can be an efficient cathode for transparent OLEDs because of its high transparency and low resistivity [8]. The Ca layer, which has a low work-function, makes an easy injection of electrons, whereas the Ag capping layer improves the lateral electrical conductance of the cathode [8,9].

Because the light generated inside the device is emitted out of the cathode and anode sides in transparent OLEDs, the emission characteristics, such as efficiency and electroluminescence spectrum, may be different on both sides, by the several factors, such as the microcavity effect and transmittance of electrodes. In this paper, we have investigated the emission characteristics of transparent OLEDs with semitransparent $\mathrm{Ca} / \mathrm{Ag}$ cathodes on the 
cathode and anode sides. We have studied the effects of an Ag capping layer on the luminance, electroluminescence spectrum, and current efficiency characteristics of transparent OLEDs. We will discuss the emission characteristics of transparent OLEDs on both sides in terms of microcavity effect and optical characteristics of electrodes.

\section{EXPERIMENTAL DETAILS}

Transparent OLEDs were fabricated on ITO-coated glass substrates. The sheet resistance of the ITO film was about $10 \Omega / \mathrm{sq}$. After defining ITO anode patterns using a standard photolithography process, the substrates were cleaned with isopropyl alcohol and deionized water. Then, the patterned ITO substrates were exposed to oxygen plasma. All the organic and metal layers were deposited using a vacuum thermal evaporation method in a base pressure of about $1 \times 10^{-6}$ Torr. A $70 \mathrm{~nm}$-thick 4,4',4"-tris[N-(2naphthyl)-N-phenyl-amino]-triphenylamine (2-TNATA) layer was deposited on the patterned ITO substrate, and followed with the deposition of a $35 \mathrm{~nm}$-thick 4,4'-bis-[N-(1-naphthyl)-N-phenyl-amino] biphenyl ( $\alpha$-NPD) layer. Next, a $35 \mathrm{~nm}$-thick tris-(8hydroxyquinoline) aluminum $\left(\mathrm{Alq}_{3}\right)$ layer was co-deposited with 1 wt.\% fluorescent dopant, 10-(2-benzothiazolyl)-1,1,7,7tetramethyl-2,3,6,7-tetrahydro- $1 \mathrm{H}, 5 \mathrm{H}, 11 \mathrm{H}$-[1]-benzopyropyrano[6,7,8-ij]quinolizin-11-one (C545T). Then, a $30 \mathrm{~nm}$-thick bis(10-hyroxybenzo[h] quinolinato) beryllium $\left(\mathrm{Bebq}_{2}\right)$ layer was evaporated. After depositing organic layers, $\mathrm{Ca}$ and Ag layers were sequentially evaporated through a shadow mask. The Ca layer was fixed to be a $15 \mathrm{~nm}$, whereas the thickness of the $\mathrm{Ag}$ capping layer was varied from 10 to $30 \mathrm{~nm}$. Figure 1 shows the completed device structure of ITO/2-TNATA $(70 \mathrm{~nm}) / \alpha$-NPD $(35 \mathrm{~nm}) / \mathrm{Alq}_{3}: \mathrm{C} 545 \mathrm{~T}(1 \%, 35 \mathrm{~nm}) / \mathrm{Bebq}_{2}(30 \mathrm{~nm}) / \mathrm{Ca}(15 \mathrm{~nm}) /$ $\mathrm{Ag}(10 \sim 30 \mathrm{~nm})$. All of the fabricated devices were encapsulated without exposure to air in a nitrogen glove box. Current densityvoltage-luminance characteristics of the devices were measured using computer-controlled Keithley 2400 source-measure units and a calibrated fast silicon photodiode (FDS010). Electroluminescence (EL) spectra were measured with a spectroradiometer (Minolta CS1000). The transmittance and reflectance of the $\mathrm{Ca} /$ Ag cathode coated on the glass substrates were measured using a Hitachi U3410 spectrophotometer with a normal incidence of monochromatic light at the sample surface side.

\section{RESULTS AND DISCUSSION}

Figure 2(a) shows the current density curves as a function of voltage for the transparent devices with the $\mathrm{Ca} / \mathrm{Ag}$ cathode. The thickness of the Ag layer was varied from 10 to $30 \mathrm{~nm}$, whereas the Ca layer was fixed to be $15 \mathrm{~nm}$. The figure shows that the current density is not seriously changed by varying the Ag thickness, indicating that the electron injection and transport are not modified by the Ag layer, since the electron transporting $\mathrm{Bebq}_{2}$ layer is not contacted with Ag, as shown in the device structure of fig. 1. The sheet resistance of the Ca/Ag cathode was about $15 \mathrm{ohm} / \mathrm{sq}$. The Ag capping layer provides the lateral electrical conductance, while the low work-function of $\mathrm{Ca}(2.9 \mathrm{eV})$ results in easy injection of electrons from the $\mathrm{Ca} / \mathrm{Ag}$ cathode into the $\mathrm{Bebq}_{2}$ layer [10]. Figure 2(b) shows the luminance curves measured on the cathode and anode sides for the devices with $\mathrm{Ca} / \mathrm{Ag}$ cathodes. The luminance curves were measured on both electrode sides because the devices are semitransparent. The figure illustrates that the luminance curve is significantly modified by the Ag thickness. The luminance measured on the cathode side decreases with increasing Ag thickness at a fixed voltage. For example, the

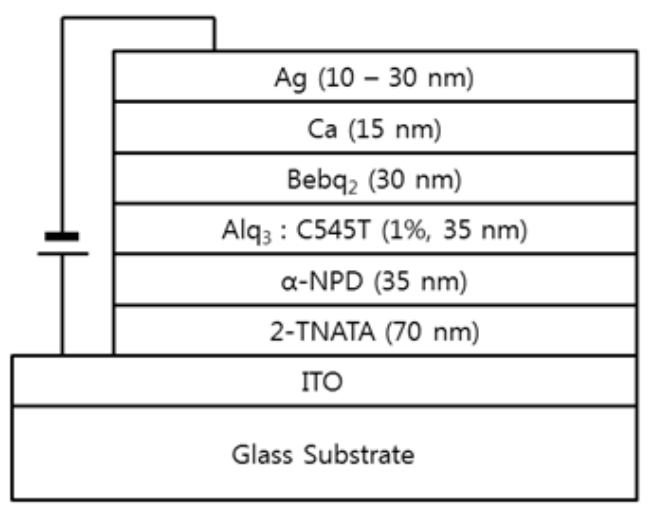

Fig. 1. Schematic structure of our transparent OLED with a Ca/Ag cathode.
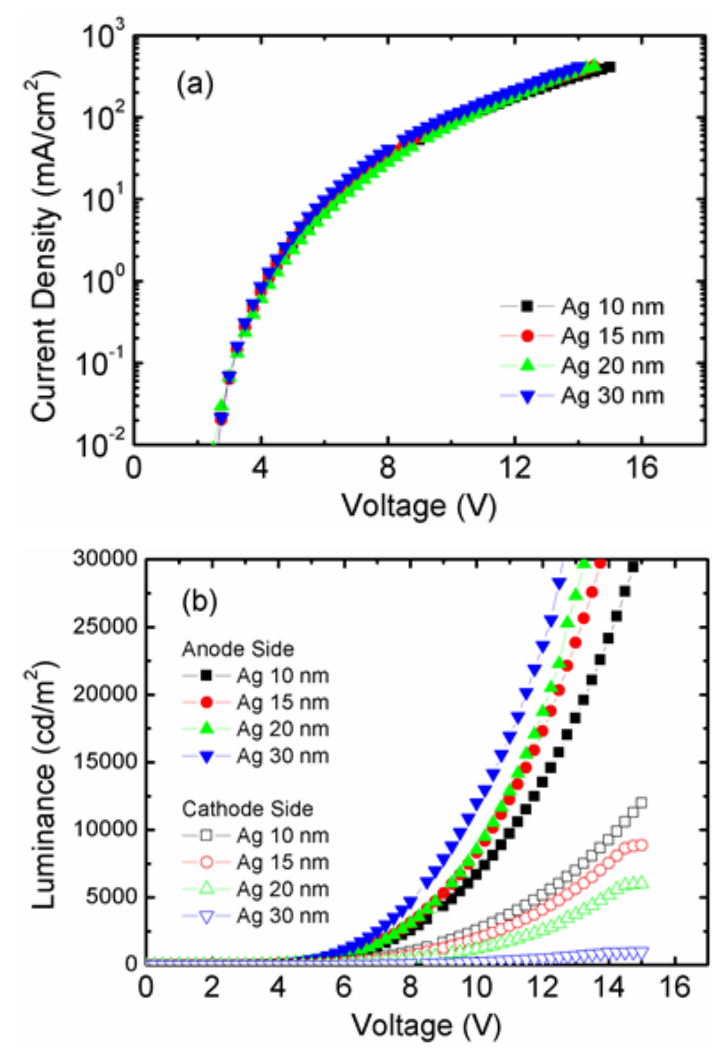

Fig. 2. Current density-voltage (a) and luminance-voltage, (b) curves measured on the cathode and anode sides for the transparent OLEDs using $\mathrm{Ca} / \mathrm{Ag}$ cathodes with various thicknesses of Ag layers.

cathode-side luminance decreases from 2,560 to $240 \mathrm{~cd} / \mathrm{m}^{2}$ at a voltage of $10 \mathrm{~V}$ as the Ag thickness increases from 10 to $30 \mathrm{~nm}$. By contrast, the anode-side luminance increases with increasing Ag thickness. For example, as the Ag thickness increases from 10 to $30 \mathrm{~nm}$, the luminance on the anode side increases from 6,690 to $11,990 \mathrm{~cd} / \mathrm{m}^{2}$ at a voltage of $10 \mathrm{~V}$. Figure 3 (a) shows the current efficiency curves on the cathode and anode sides as a function of current density for the transparent devices with various thicknesses of Ag layers. Because the current density is not influenced by the Ag thickness, as shown in fig. 2(a), the current efficiency curves are consistent with the luminance curves of fig. 2(b). As the Ag thickness increases, the cathode-side current efficiency decreases but the anode-side efficiency increases at a fixed cur- 

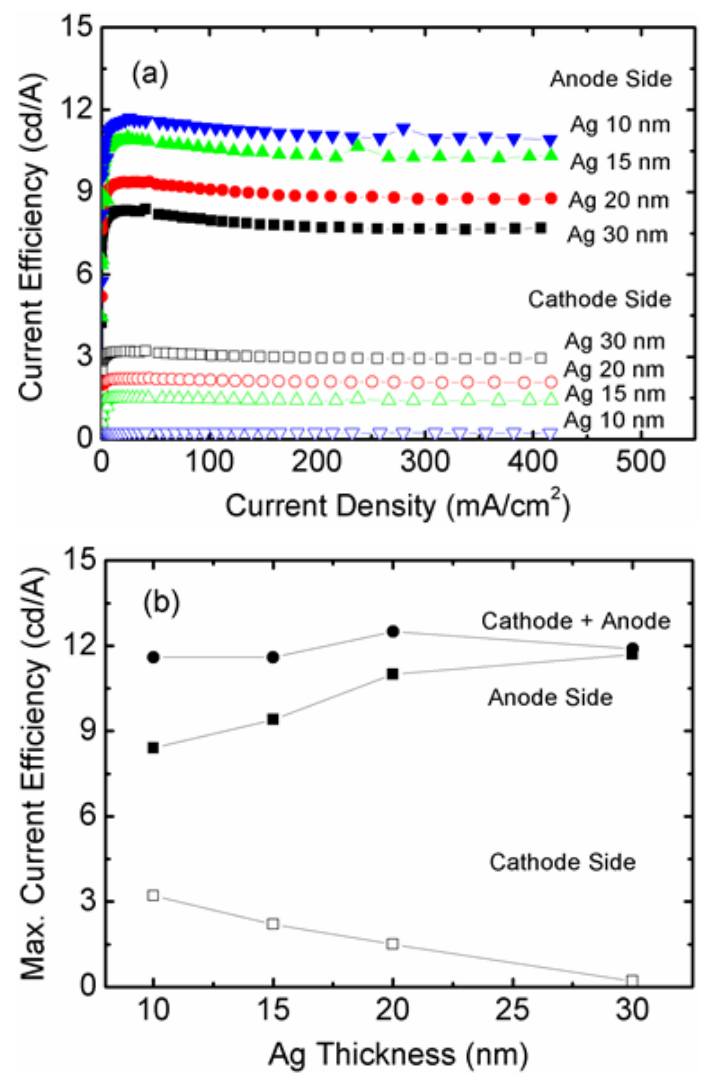

Fig. 3. Current efficiency-current density (a) and maximum current efficiency-Ag thickness, (b) curves measured on the cathode and anode sides for the transparent OLEDs using Ca/Ag cathodes with various thicknesses of Ag layers.

rent density. In fig. 3(b), the maximum current efficiency as a function of Ag thickness for the transparent devices with $\mathrm{Ca} / \mathrm{Ag}$ cathodes are clearly shown. Similar to fig. 3(a), the maximum current efficiency on the cathode side decreases from 3.2 to 0.2 $\mathrm{cd} / \mathrm{A}$, whereas, on the anode side, it increases from 8.4 to 11.7 $\mathrm{cd} / \mathrm{A}$ as the $\mathrm{Ag}$ thickness increases from 10 to $30 \mathrm{~nm}$. The figure also shows that the sum of the maximum current efficiencies on both the cathode and the anode side is almost same as the $\mathrm{Ag}$ thickness. These results suggest that the Ag thickness influences the extraction of light out of the cathode and anode, rather than the number of photons generated inside the device. The extraction efficiency on both of the electrode sides may be altered by the microcavity effects, because the reflective Ag layer may cause multiple interferences [12]. Figure 4 shows the electroluminescence spectra measured on the cathode and anode sides for the transparent devices with various Ag thicknesses. The emission spectrum on both electrodes is not changed significantly but it is narrowed slightly by increasing Ag thickness, thus indicating the weak microcavity effects [13]. The finding suggests that the changes in the extraction of light on both electrodes by varying the Ag thickness may be caused by the transmittance and reflectance of the cathode rather than the multiple interference effects between both electrodes.

Figure 5 shows the transmission and reflection spectra for the $\mathrm{Ca} / \mathrm{Ag}$ cathode with different thicknesses of Ag layers coated on the glass substrates. As the Ag-layer thickness increases, the transmittance of the $\mathrm{Ca} / \mathrm{Ag}$ cathode decreases, whereas the reflectance increases. For example, fig. 5(a) shows that the transmittance of the $\mathrm{Ca} / \mathrm{Ag}$ decreases from $62 \%$ to $21 \%$ at the wavelength of $520 \mathrm{~nm}$, which is the emission wavelength of the
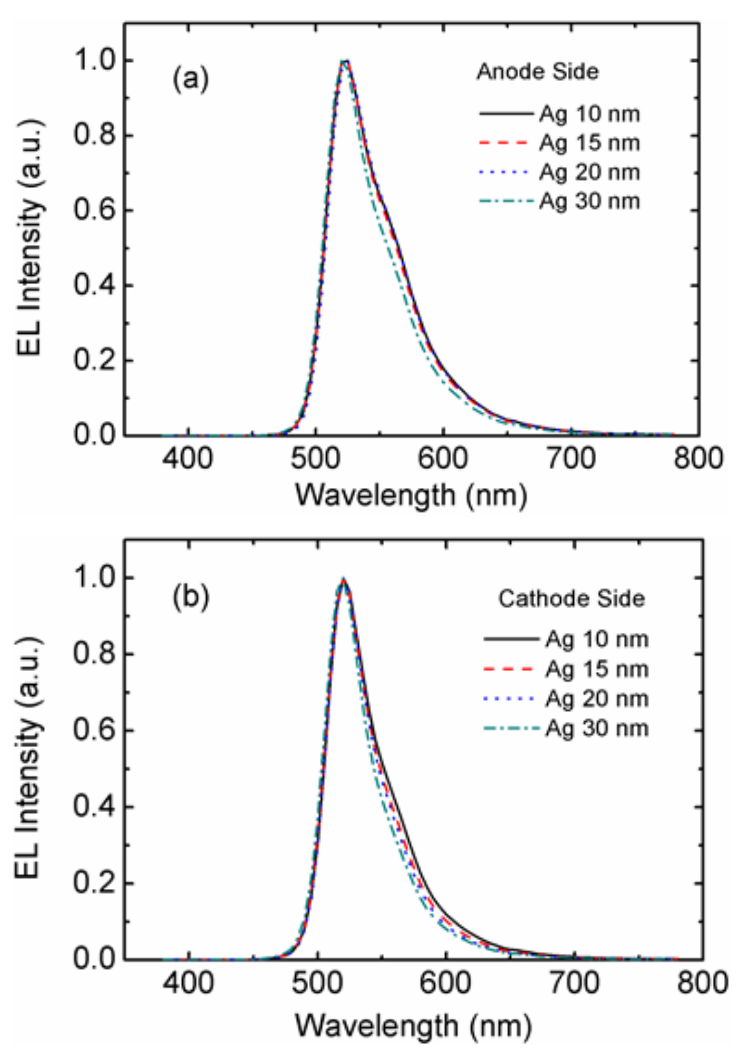

Fig. 4. EL spectra measured on the anode (a) and cathode, (b) sides for the transparent OLEDs using $\mathrm{Ca} / \mathrm{Ag}$ cathodes with various thicknesses of Ag layers.
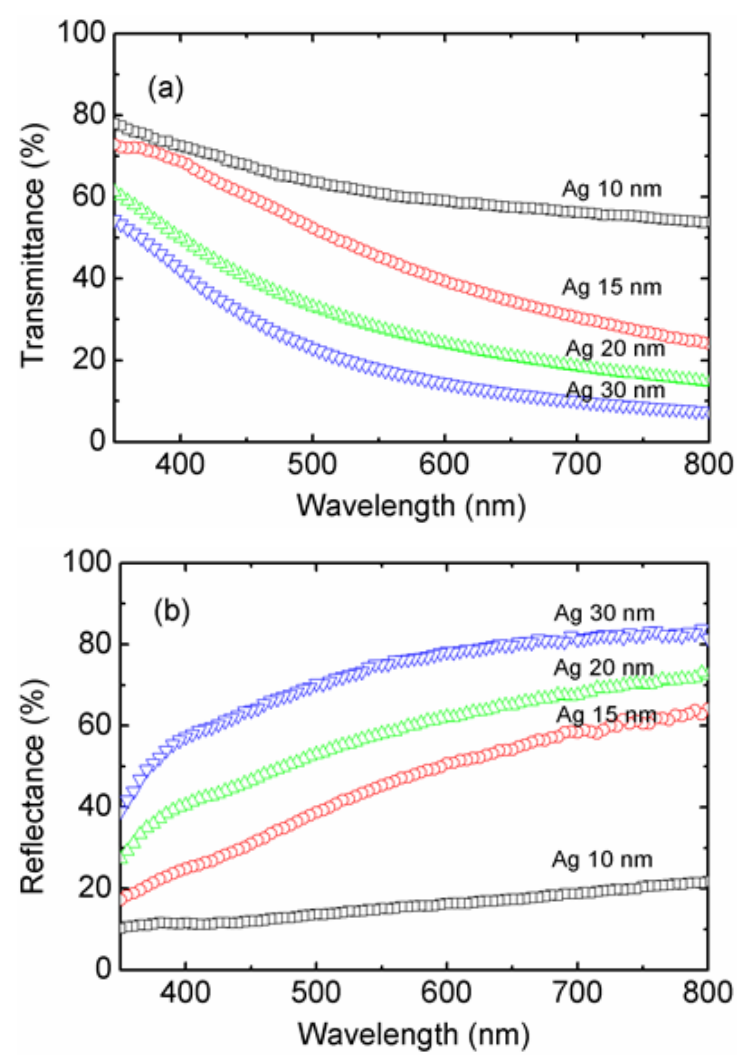

Fig. 5. Transmission (a) and reflection, (b) spectra for the Ca/Ag cathodes coated on the glass substrates with various thicknesses of Ag layers. 
fluorescent dopant, C545T molecule, as the Ag thickness increases from 10 to $30 \mathrm{~nm}$. That finding indicates that the extraction of light out of the Ca/Ag cathode decreases with the increasing Ag thickness, which results in the decrease of luminance and current efficiency on the cathode side. However, fig. 5(b) shows that the reflectance increases from $24 \%$ to $72 \%$ at the $520 \mathrm{~nm}$ as the Ag thickness increases from 10 to $30 \mathrm{~nm}$. Thus, the reflection of light by the $\mathrm{Ca} / \mathrm{Ag}$ cathode increases by increasing the Ag thickness. The reflected light is moving toward the ITO anode, and extracted out of the anode because the ITO electrode has a sufficiently high transmittance of $90 \%$ and low reflectance of about $1 \%$ in our devices, such that the luminance and current efficiency on the anode side increases as the Ag thickness is increased. It also should be noted that the luminance and current efficiencies on the cathode side are lower than those on the anode side in the $t$ Ag-layer thickness range of $10 \sim 30 \mathrm{~nm}$,, as shown in the fig. 2 and 3 , since the transmittances $(20 \sim 60 \%)$ of the $\mathrm{Ca} / \mathrm{Ag}$ cathode with the Ag layer of 10 30 nm are lower than that $(90 \%)$ of the ITO anode in our devices.

\section{CONCLUSIONS}

We have investigated the effects of an Ag capping layer on the emission characteristics of transparent OLEDs with Ca/Ag cathodes. The extraction of light generated inside the emission layer out of the cathode and anode is determined by the transmission and reflection of the Ag layer. As the thickness of the Ag layer increases, the current efficiency measured on the cathode side decreases because the transmission of light through the cathode decreases while the reflection of light increases by the reflective Ag layer. In contrast, the anode-side efficiency increases with increasing Ag-layer thickness, as the reflected light by the Ag layer is extracted out of the anode.

\section{REFERENCES}

[1] C. W. Tang and S. A. VanSlyke, Appl. Phys. Lett., 51, 913 (1987) [DOI: http://dx.doi.org/10.1063/1.98799].

[2] B. W. D'Andrad and S. R. Forrest, Adv. Mater., 16, 1585 (2004) [DOI: http://dx.doi.org/10.1002/adma.200400684].

[3] P. E. Burrows and S. R. Forrest, Appl. Phys. Lett., 64, 2285 (1994) [http://dx.doi.org/10.1063/1.111645].

[4] L. S. Hung, C. W. Tang, M. G. Mason, P. Raychaudhuri, and J. Madathil, Appl. Phys. Lett., 78, 544 (2001) [DOI: http://dx.doi. org/10.1063/1.1327273].

[5] G. G. Qin, A. G. Xu, G. L. Ma, G. Z. Ran, Y. P. Qiao, B. R. Zhang, W. X. Chen, and S. K. Wu, Appl. Phys. Lett., 85, 5406 (2004) [DOI: http://dx.doi.org/10.1063/1.1823601].

[6] S.L. Lai, M. Y. Chan, M. K. Fungs, C. S. Lee, L. S. Hung, and S. T. Lee, Chem. Phys. Lett., 366, 128 (2002) [DOI: http://dx.doi. org/10.1016/S0009-2614(02)01553-1].

[7] H. Riel, S. Karg, T. Beierlein, B. Ruhstaller, and W. Rieß, Appl. Phys. Lett., 82, 466 (2003) [DOI: http://dx.doi. org/10.1063/1.1537052].

[8] R. B. Pode, C. J. Lee, D. G. Moon, and J. I. Han, Appl. Phys. Lett., 84, 4614 (2004) [DOI: http://dx.doi.org/10.1063/1.1756674].

[9] C. J. Lee, R. B. Pode, D. G. Moon, and J. I. Han, Thin Solid Films, 467, 201 (2004) [DOI: http://dx.doi.org/10.1016/ j.tsf.2004.04.016].

[10] C. J. Lee, R. B. Pode, J. I. Han, and D. G. Moon, Appl. Phys. Lett., 89, 123501, (2006) [DOI: http://dx.doi.org/10.1063/1.2355464].

[11] S. Y. Kim, D. G. Moon, C. J. Lee, and J. I. Han, Thin Solid Films, 517, 2035 (2009) [DOI: http://dx.doi.org/10.1016/ j.tsf.2008.10.003].

[12] H. Riel, S. Karg, T. Beierlein, B. Ruhstaller, W. Rieß, and K. Neyts, J. Appl. Phys., 94, 5290 (2003) [DOI: http://dx.doi. org/10.1063/1.1605256].

[13] V. Bulvíc, V. B. Khalfin, G. Gu, P. E. Burrows, D. Z. Garbuzov, and S. R. Forrest, Phys. Rev. B, 58, 3730 (1998) [DOI: http://dx.doi. org/10.1103/PhysRevB.58.3730]. 